\title{
Identification of three independent fern gametophytes and Hymenophyllum wrightii f. serratum from Korea based on molecular data
}

\author{
Chang Shook LEE*, Kanghyup LEE ${ }^{1}$ and Youngsim HWANG ${ }^{2,3}$ \\ Department of Science Education, Ewha Womans University, Seoul 03760, Korea \\ ${ }^{1}$ Korea National Arboretum, Pocheon 11186, Korea \\ ${ }^{2}$ Department of Environmental Science and Ecological Engineering, Korea University Seoul 02841, Korea \\ ${ }^{3}$ Geobook, Seoul 03170, Korea
}

(Received 19 November 2020; Revised 13 December 2020; Accepted 23 December 2020)

\begin{abstract}
Colonies of three independent gametophytes (one that is filamentous and two that are ribbon-like) without sporophytes occur in Gyeonggi-do, Gangwon-do, Gyeongsang-do, and Jeju-do, Korea. They have a moss-like appearance at first sight, with tiny plantlets and gemmae, and grow in cool, shaded, relatively deep dint places of large rocks, such as the small caves in high mountains, close to valleys. The gametophytes were identified based on morphological and molecular data by chloroplast DNA (cpDNA) sequence data ( $r b c L, r p s 4$ gene and rps4-trnS intergenic spacer). Here, $r b c L$, rps4 gene and rps4-trnS intergenic spacer data of one independent gametophyte distributed in Korea have the same morphology, DNA sequence and monophyletic group as Crepidomanes intricatum from the eastern United States. They also share the same cpDNA data with Crepidomanes schmidtianum recently reported from Korea. The other independent gametophyte should be Hymenophyllum wrightii based on cpDNA data. The last one was presumed to be Pleurosoriopsis makinoi based on molecular data. The taxonomic status was confirmed to be the forma of Hymenophyllum wrightii through a revision of Hymenophyllum wrightii f. serratum based on molecular data.
\end{abstract}

Keywords: independent gametophytes, Hymenophyllum wrightii f. serratum, cpDNA, molecular data

Ferns as seed plants have life cycles of two completely freeliving phases: a long-lived sporophytes phase and shorter-lived gametophytes phase. This is in contrast to seed plants, which comprise of a few less visible short-lived gametophytes protected within sporophytes. Although most ferns follow the standard alternation of generations cycle closely, the independence of these two life stages allows for both the gametophyte and sporophyte to explore novel ecological niches (Sato and Sakai, 1981) and life history strategies (Dassler and Farrar, 2001). In some ferns, however, if their environment is poor, the gametophyte phase will mainly be in the asexual stage, and the sporophyte stage, as a diploid sexual stage will be rare or possibly non-existent.

In many epiphytic fern species, the gametophyte is capable of vegetative growth, and some can reproduce asexually via gemmae. An epiphytic habitat presumably provides advantages to persistence through vegetative growth and branching, often producing bryophyte-like colonies (Ebihara et al., 2008; Farrar et al., 2008). Those noncordiform gametophytes characters producing gemmae without producing sporophyte have increased the independent gametophytes as separation of generation (Pinson et al., 2016).

These independent gemmiferous fern gametophytes in filmy ferns (Hymenophyllaceae), vittarioid ferns (Pteridaceae), and grammatid ferns (Polypodiaceae) are usually found in temperate zones from the eastern United States, northeastern Canada, Europe, and Japan (Farrar, 1967, 1985, 1990, 1992; Rumsey et al., 1998; Krukowski and Swierkoz, 2004; Ebihara et al., 2008; Duffy et al., 2015; Pinson et al., 2016; Ebihara et al., 2019). Such independent gametophytes are limited to temperate zones as a hypothesized stable vegetation that appeared to be less affected by climate change during

*Author for correspondence: ferncslee@hanmail.net 
glaciations (Harrison et al., 2001). Nevertheless, these independent gametophytes of two vittarioid ferns were recently discovered in nontemperate regions, subtropical Taiwan (Kuo et al., 2017).

During field work in 2014, new bryophyte-like colonies of independent gametophyte (one filamentous) growing without any sporophytes were firstly found on a deep dint place of large rock in a small cave high in Hwayasan Mt. in Gyeonggido province, Korea, on February 2014. They had a moss-like appearance at first sight and possessed gemmae. The colonies were distributed broadly on a relatively deep dint place of a large rock in a small cave in the high mountain, which was around valley. To find other colonies of the independent gametophytes, similar habits of high mountains in Gangwondo, Gyeonggi-do, Gyeongsang-do, and Jeju-do were surveyed from 2014 until 2019. Another independent gametophyte (ribbon-like) was found on deep dint place of a large rock in a province from Korea. These independent gametophytes in Korea were first recorded by Lee and Lee $(2015,2018)$ as Crepidomanes schmidtianum, Hymenophyllum wrightii, and Pleurosoriopsis makinoi based on the morphology. Park et al. (2020) found independent gametophyte of Antrophyum obovatum only in Jeju Island from Korea.

The Sporophytes of Crepidomanes schmidtianum were distributed in Mt. Jirisan, Korea as the first recorded species (Lee et al., 2014a). The genus Crepidomanes was treated as a single large genus (Morton, 1968) as Trichomanes or split into several smaller genera (Ebihara et al., 2006) as Crepidomanes. Ebihara et al. (2008) compared the chloroplast genomes between the sporophyte-less filmy fern $T$. intricatum in the eastern United States and C. schmidtianum in Japan to investigate their relationship based on the $r b c L$ sequences. As the result, they presumed that $T$. intricatum should be treated as a synonym of $C$. schmidtianum (Ebihara et al., 2008). Some authors identified it as C. intricatum (Duffy et al., 2015; Pinson et al., 2016).

These findings suggest that climate change during Pleistocene resulted in ecophysiological maladaptation of nontemperate in dependent gametophyte ferns, resulting in postzygotic sterility by eliminating their sporophytes (Kuo et al., 2017).

Identifying ferns to genus and species level based on gametophyte morphology is difficult because of the fern gametophyte size and cryptic morphology (Schneider and Schuettpelz, 2006; Watkins et al, 2007; Li et al., 2009). Nevertheless, identifying the genus or subgenus is often possible in taxonomic groups from the gametophyte morphologies (Farrar et al., 2008). Recent studies of gametophyte ecology applied molecular methods to conserve the new insights (Ebihara et al., 2008; Duffy et al., 2015; Pinson et al., 2016; Kuo et al., 2017).

To identify the independent gametophytes and verify their presence in Korea, it was an analysis of morphological characteristics and molecular data was carried out using the chloroplast DNA (cpDNA) sequence of $r b c L$ and $r p s 4-t r n S$ (rps4 gene and rps4-trnS intergenic spacer [IGS]) regions of cpDNA.

Hymenophyllum wrightii f. serratum C. S. Lee \& K. Lee (Hymenophyllaceae) was published as a new taxon of Hymenophyllum wrightii based on their smaller leaves, broader basal part of the leaf blade, broad-ovate laminae, larger sori, and serrate margins of lips of involucres (Lee et al., 2014b). The taxonomic status of Hymenophyllum wrightii f. serratum was inferred based on an analysis of the cpDNA data of $r b c L$ and rps4-trnS (rps4 gene and rps4-trnS IGS) regions of this taxon with the related taxa.

\section{Materials and Methods}

The sources of plant materials for morphology and DNA analysis and GenBank accession numbers are listed in Appendix 1. All leaf materials were obtained from natural populations in Korea, 100-200 gametophyte cells or $1 \mathrm{~cm}^{2}$ of sporophyte leaf tissue was used for DNA extraction with a DNease Plant Mini Kit (Ebihara et al., 2008). A total of 14 accessions for $r b c L$ sequences and 14 accessions for rps4-trnS (rps4 gene and rps4-trnS IGS) sequence data were newly analyzed (Appendix 1), and outgroup and several ingroup data (34 accessions) were obtained from GenBank.

In order to identify three independent gametophytes (Crepidomanes schmidtianum, Hymenophyllum wrightii, and Pleurosoriopsis makinoi), it was added newly 10 accessions from Korea and 3 accessions from DNA bank (Ebihara et al., 2008; Duffy et al., 2015) for cpDNA sequence of $r b c L$ and rps4-trnS (rps4 gene and rps4-trnS IGS) regions of cpDNA. In comparing the molecular analysis, the sporophytes of three taxa was added newly 4 accessions sampled from Korea, and 10 accessions gotten from DNA bank (Hasebe et al., 1994; Ebihara et al., 2007, 2008; Kim et al., 2013). And we got newly 5 accessions and 16 accessions from DNA bank (Hasebe et al., 1994; Schneider et al., 2004; Kreier and Schneider, 2006; Ebihara et al., 2007, 2010; Wang et al., 2010; Nitta et al., 2011), which examined from one taxon of Polypodium, two taxa of Pyrrosia, one taxon of Colysis, and two taxa of Lepisorus for outgroup.

Moreover, to evaluate the status of Hymenophyllum wrightii 
f. serratum, we sampled 4 accessions from Jeju-do, Korea. In comparing the molecular analysis, we aligned with the related taxa, above mentioned $H$. wrightii, newly 1 accession of $H$. polyanthos, 4 accessions of $H$. barbatum from Korea, and 5 accessions gotten from DNA bank (Hasebe et al., 1994; Kim et al., 2013; Vasques et al., 2019).

Total genomic DNA was extracted using the DNeasy plant mini kit (Qiagen Inc., Valencia, CA, USA). Primers used for amplification and sequencing were $r b c L$-TKT-F1 and $r b c L$-TKTR3N-2 for the $r b c L$ gene (Ebihara et al., 2005), trnS (TACCGAGGGTTCGAATC) (Souza-Chies et al., 1997; Smith and Cranfill, 2002), the rps4F1 (RPSF1 GCCGCTAGACAATT AGTCAATC) (Hennequin et al., 2003) for part of the rps4 gene and rps4-trnS IGS (Schneider et al., 2004). Amplification was conducted using a PTC-100 thermal cycler (MJ Research, Watertown, MA, USA) with the following temperature profile for all regions: a 32 to 37 cycle reaction with denaturalization at $94^{\circ} \mathrm{C}$ for $1 \mathrm{~min}$, annealing at $54^{\circ} \mathrm{C}$ for $1 \mathrm{~min}$ and extension at $72^{\circ} \mathrm{C}$ for 2 to $3 \mathrm{~min}$. In addition, an initial denaturalization at $94^{\circ} \mathrm{C}$ for $2.5 \mathrm{~min}$ and a final extension at $72^{\circ} \mathrm{C}$ for $10 \mathrm{~min}$ were performed. PCR products were purified with AccuPrep PCR Purification Kit (Bioneer Inc., Daejeon, Korea). Automated sequencing analysis was performed using a sequencer (Base station, MJ Research).

Nucleotide sequences of cpDNA regions were each aligned with default alignment parameters, using the Clustal X program (Thompson et al., 1997) with final manual adjustment (Gibson et al., 1994; Thompson et al., 1997). The two data matrices were analyzed initially using maximum parsimony (MP) by PAUP* (Swofford, 2002), treating gaps with massing values, and later in separate analyses. Heuristic MP searches were replicated 1000 random stepwise addition of taxa, treebisection-reconnection (TBR) branch swapping, and saving multiple trees. Bootstrap values (Felsenstein, 1985) were calculated from 100 replicate analyses using TBR branch swapping and simple stepwise addition of taxa.

\section{Results and Discussion}

\section{Morphology and distribution of three independent gametophytes}

The natural habits of independent gametophytes of Crepidomanes schmidtianum, Hymenophyllum wrightii, and Pleurosoriopsis makinoi are the relatively deep dint place of large rocks, such as small caves in the high mountains around a valley, as shown in Fig. 1. They have a moss-like appearance at first sight and have gemmae. The filamentous gametophyte type has been observed in C. schmidtianum, and ribbon like gametophyte morphology has been observed in $H$. wrightii and Pleurosoriopsis makinoi (Table 1). The gemmae shape of $H$. wrightii is linear, $C$. schmidtianum has filamentous linear gemmae. P. makinoi has round or oblong gemmae (Fig. 1). Among these three taxa, many rhizoids were observed only in H. wrightii.

The filamentous type, gametophytes of Crepidomanes schmidtianum were found in the deep dint place of moist rocks, such as small caves of high mountains around valley: Hwayasan Mt. in Gyeonggi-do province and Seolarksan Mt., Taebaeksan Mt. in Gangwon-do from Korea (Fig. 2). This independent gametophyte in Korea has the same morphology as the sporophyte-less, independent gametophytes of Trichomanes intricatum, which is treated as the synonym of C. schmidtianum, and is distributed widely in the eastern United States (Farrar, 1990; Ebihara et al., 2008). The sporophytes of C. schmidtianum were collected from forests in Jirisan Mt., Baegmu-dong, Macheon-myeon, Gyeongsangnam-do from Korea. The sporophytes of this taxon are distributed from Himalaya region to Japan (Iwatsuki, 1985). In the eastern United States, this taxon has been producing sporophytes only as occasional sterile juveniles or not producing sporophytes at all (Ebihara et al., 2008). Interestingly, C. schmidtianum is distributed far apart in Korea alone, both in form of independent gametophytes and sporophytes.

Table 1. Morphological characters and distributions of three independent gametophytes.

\begin{tabular}{lccc}
\hline \hline \multicolumn{1}{c}{ Characters } & Crepidomanes schmidtianum & Hymenophyllum wrightii & Pleurosoriopsis makinoi \\
\hline Gametophytes morphology & Filamentous & Ribbon like & Ribbon like \\
$\begin{array}{l}\text { Gemmae shape } \\
\text { Rhizoids }\end{array}$ & Filamentous linear & Linear & Round or oblong \\
$\begin{array}{l}\text { Distribution of independent } \\
\text { gametophytes }\end{array}$ & Absent & Many present & A little present \\
Uistribution of sporophytes & East-central Asia & Northwestern America (Washington, and Alaska & Japan, Korea \\
& & of USA, British Colombia of Canada), Jeju & Island of Korea \\
& & Northwestern America (Haida Gwaii, British & East Asia \\
& Columbia of Canada), East Asia (Jeju Island of & Korea; Japan; Far east of Russia) \\
\end{tabular}




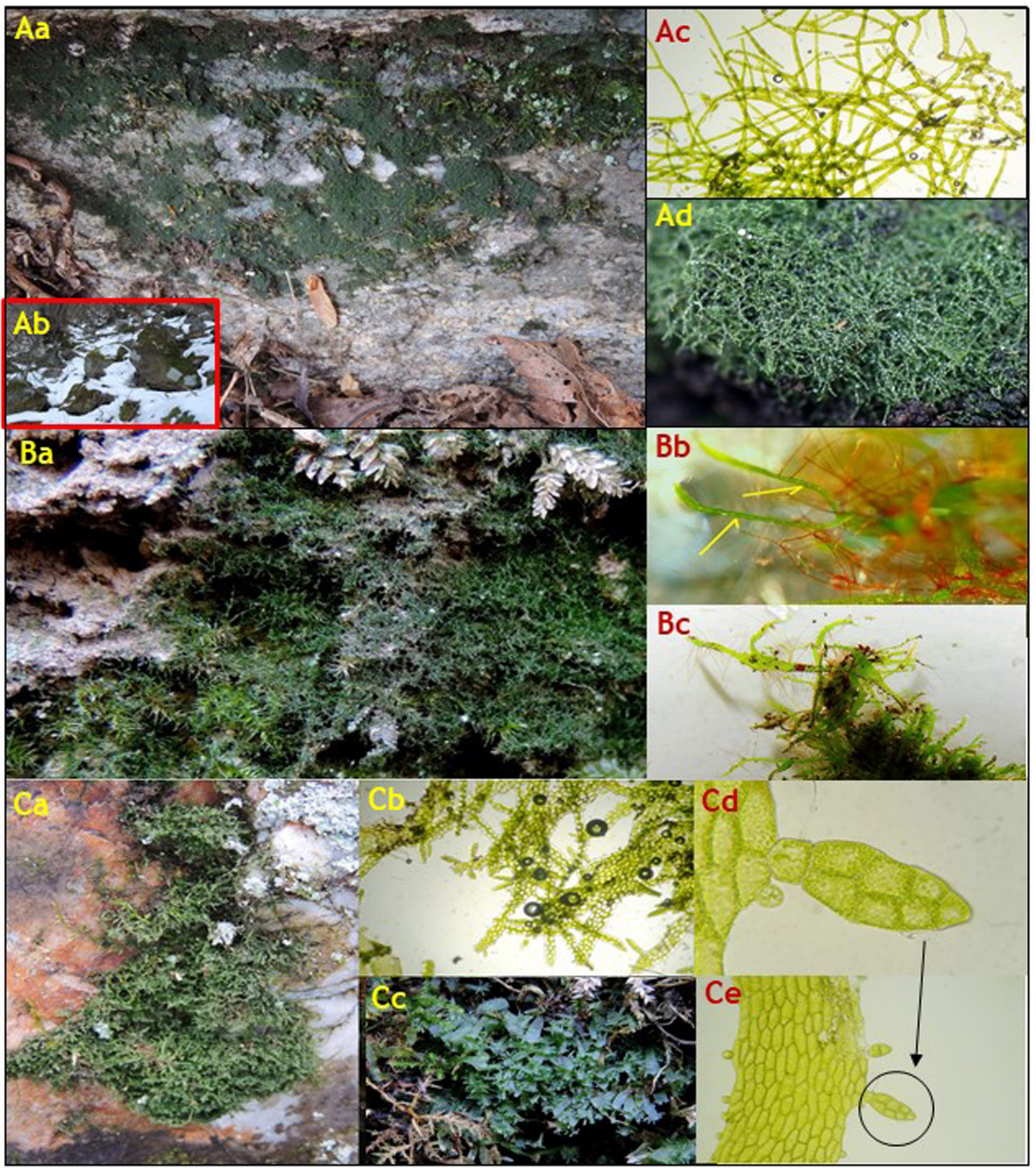

Fig. 1. Photographs of colonies of ribbon like or filamentous independent gametophytes. A. Crepidomanes schmidtianum distributed on the rock at the high mountain, the site $500 \mathrm{~m}$ height of Gangwon-do in Korea. a, b. Habit. c, d. Filamentous independent gametophytes. B. Hymenophyllum wrightii distributed on the rock of Jeju-do. a. Habit. b, c. Ribbon like independent gametophytes. C. Pleurosoriopsis makinoi distributed on the rock of Gyeonggi-do. a, c. Habit. b. Ribbon like independent gametophytes. d, e. Microscopic view of gametophyte with gemmae.

Ribbon like gametophytes of Hymenophyllum wrightii were collected in Jejudo Island in this study (Fig. 2). Park et al. (2020) collected them from seven sites in Jeju Island located at altitudes ranging from $200 \mathrm{~m}$ to $700 \mathrm{~m}$. The sampling in the present study contained this species. The gametophytes of $H$. wrightii were not present, and sporophytes were found only in Japan (Ebihara, 2016; Park et al., 2020). On the other hand, the species in Northwestern America have been reported to 


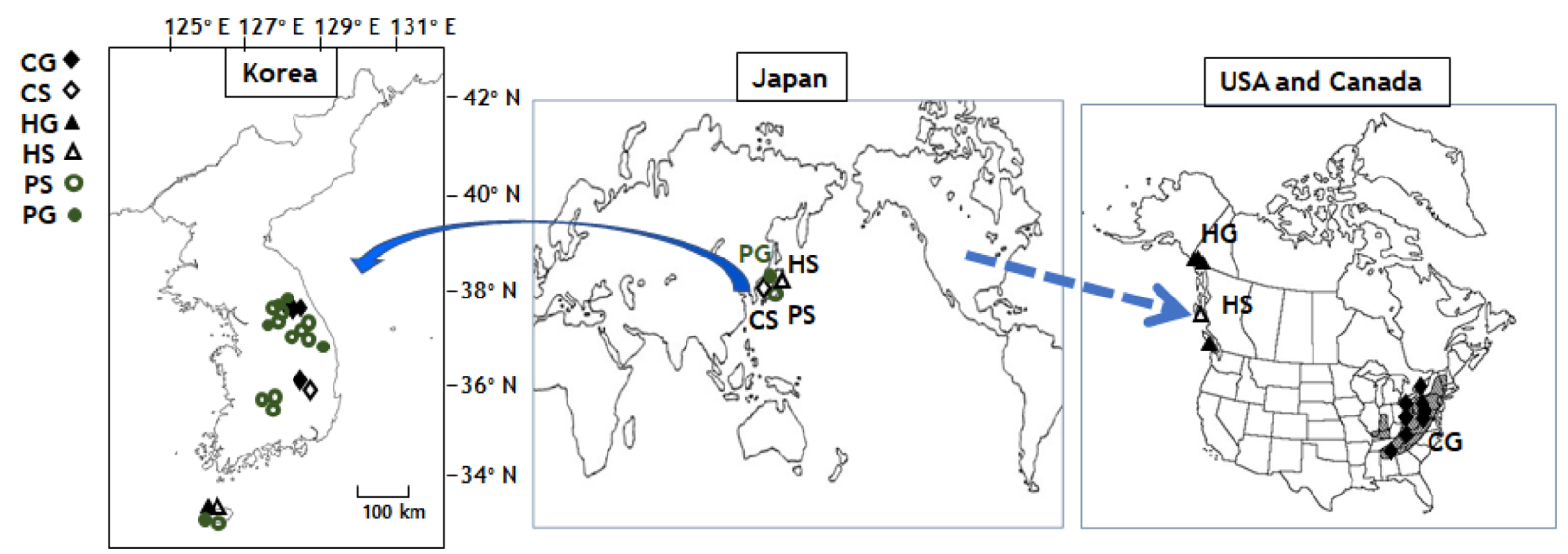

Fig. 2. Map of three independent gametophytes and sporophytes, Crepidomanes schmidtianum (=C. intricatum) (C), Hymenophyllum wrightii (H), and Pleurospriopsis makinoi (P). G, independent gametophytes; S, sporophyte.

have a wide distribution from Washington State up to parts of British Colombia and Alaska (Duffy et al., 2015). Sporophytes of $H$. wrightii is distributed on rocks or tree trunks in wet forests in Korea, Japan, and Russia (Sakhalin) of east Asia, and are found on dark, shady, wet cliffs near sea level of coast in of Northwestern Canada (Duffy et al., 2015; Lee and Lee, 2015, 2018; Ebihara, 2016). Unlike the wide distribution of gametophytes, the sporophytes of $H$. wrightii were rarely found in Gyeongsangnam-do and Jejudo Island of Korea as in Haida Gwaii of Northwest Canada (Duffy et al, 2015; Lee and Lee, 2018). In Japan, the sporophytes of $H$. wrightii were distributed widely without independent gametophytes (Ebihara, 2016). The gametophytes of $H$. wrightii were distributed in Jeju Island, Korea, located near sporophytes. In North America, however, the more widely distributed gametophytes of this taxon in the lowland coast of Northwest America were located far from sporophytes (Duffy et al., 2015). Park et al. (2020) suggested that $H$. wrightii spreads from Japan to northeast Asia and North America, but environmental changes, such as aridity, temperature, or light conditions (Makgomol and Sheffield, 2001; Ebihara et al., 2019) suppress the growth of sporophytes. Although this explanation appears reasonable, a detailed study based on environmental factors or biogeographic level will be needed to confirm the rapid disappearance of sporophytes and only the presence of gametophytes.

Ribbon like gametophytes of Pleurosoriopsis makinoi were found in on deep dint place of moist rock, such as small caves in humid mountains around a valley in Sangsan Mt., Kwangdeoksan Mt. in Gyeonggi-do province and Seolarksan Mt., Taebaekwsan Mt. in Gangwon-do, and Jeju-do from Korea (Fig. 2). Ebihara et al. (2019) reported that the gametophytes of P. makinoi were found occasionally in Unazawa Valley,
Okutama-machi, Tokyo, Japan without sporophytes. Sporophytes of P. makinoi form small populations on the Korean Peninsula, but they are widely spread (Fig. 2). In Japan, the sporophytes of P. makinoi are difficult to find (Ebihara et al., 2019). A more detailed examination of the distribution will be needed to explain the biogeographic evolution.

\section{Molecular data analysis of three independent gametophytes and Hymenophyllum wrightii $\mathrm{f}$. serratum}

The aligned length of $r b c L$ region is 1,200 bp, and aligned length of the rps 4 gene and rps4-trnS IGS region is $804 \mathrm{bp}$. Of the 1,200 aligned $r b c L$ region, 845 sites (70.4\%) were identical, 38 sites $(3.17 \%)$ are parsimony uninformative, and 317 sites $(26.4 \%)$ provide phylogenetic information. MP analysis of the entire $r b c L$ sequences reveled two retained trees with a tree length (TL) of 591, a consistency index (CI) of 0.7191 (0.6998 excluding uninformative characters), and a retention index (RI) of 0.9363 . Fig. 3 presents one of the two equally most parsimonious trees. Because all the parsimony trees and a strict consensus tree have similar topologies on positions and relationships of ingroups, one of parsimony tree is presented.

In the $804 \mathrm{bp}$ aligned rps 4 gene and rps4-trnS IGS region, 244 sites (33\%) were identical, 59 sites (7.3\%) were parsimony uninformative, and 501 sites $(62.3 \%)$ provide phylogenetic information. MP analysis of the entire rps4 gene and rps4-trnS IGS sequence found 1,034 equally most parsimonious trees with $1 \mathrm{TL}$, with a high CI $(0.8211$ or 0.8097 excluding uninformative characters) and RI (0.9434). Fig. 4 presents one of the equally most parsimonious tree. Because all the parsimony trees and a strict consensus tree have similar 


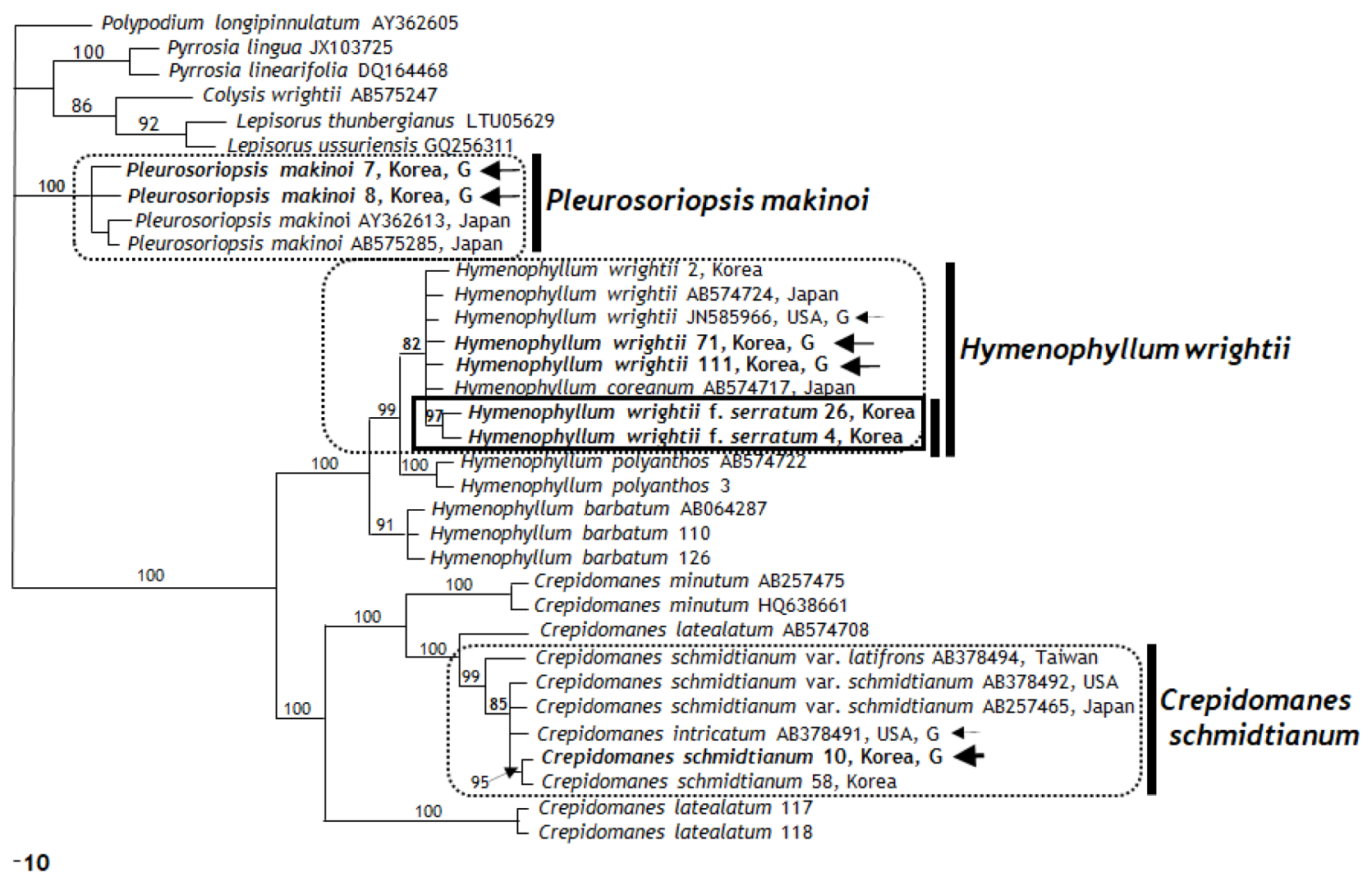

Fig. 3. Phylogenetic tree of three independent gametophytes, Hymenophyllum wrightii f. serratum, and related taxa deduced from $r b c L$ data. Bootstrap values $(>50 \%)$ by maximum parsimony method are shown above branches. Arrow and G, independent gametophytes.

topologies on positions and relationships of ingroups, one of parsimony tree is presented.

$r b c L$ region analysis showed that the filamentous gametophyte and sporophyte of Crepidomanes schmidtianum from Korea and sporophyte of C. schmidtianum from Japan (GenBank AB257465, AB378492) (Ebihara et al., 2008) with the gametophyte of $C$. intricatum from United Staes (GenBank AB378491) (Ebihara et al., 2008) formed a monophyletic clade with an $85 \%$ bootstrap value (Fig. 3). In contrast, $C$. schmidtianum exhibits two haplotypes refracting the geographic patterns: Japan (accession no. AB257426) and Korea types (accessions no. 10, 58) (Fig. 3). Among the aligned $1,205 \mathrm{bp}$, only two nucleotide positions $(0.1 \%)$ had different sequences. In an analysis of the rps4 genes and rps4-trnS IGS region (aligned $804 \mathrm{bp}$ ), the gametophytes and sporophytes of C. schmidtianum from Korea and sporophyte from Japan (GenBank AB378497) (Ebihara et al., 2008) formed a clade with the strong support of a $100 \%$ bootstrap value. Among them, three different nucleotide positions (0.37\%) were detected. Based on the strong bootstrap value and $99 \%$ sequences, the independent gametophytes of C. schmidtianum from Korea are present in Korea. These results are supported by morphological features, such as filamentous gametophyte, filamentous linear gemmae, and rhizoid absence (Ebihara et al., 2008). The cpDNA data of one independent gametophyte distributed from Korea has the same sequence and monophyletic group as Crepidomanes intricatum from eastern United States. Moreover, it shares the same cpDNA data of Crepidomanes schmidtianum newly reported from Korea (Lee et al., 2014a). This result strongly suggests that it should be same species, even although there may have been the same female parent between two taxa (Ebihara et al., 2008). Interestingly, two newly obtained accessions $(117,118)$ and one accession gotten from GenBank (AB574708) of $C$. latealatum, did not form a group according to their taxonomic species. Big difference of sequences shows the possibility of mis-identification.

$r b c L$ region analysis showed that the gametophytes and sporophytes of Hymenophyllum wrightii from Korea, sporophyte from Japan (GenBank AB574724) (Ebihara et al., 2010), and gametophytes of United States (GenBank JN585966) (Duffy et al., 2015) with the sporophytes of $H$. 


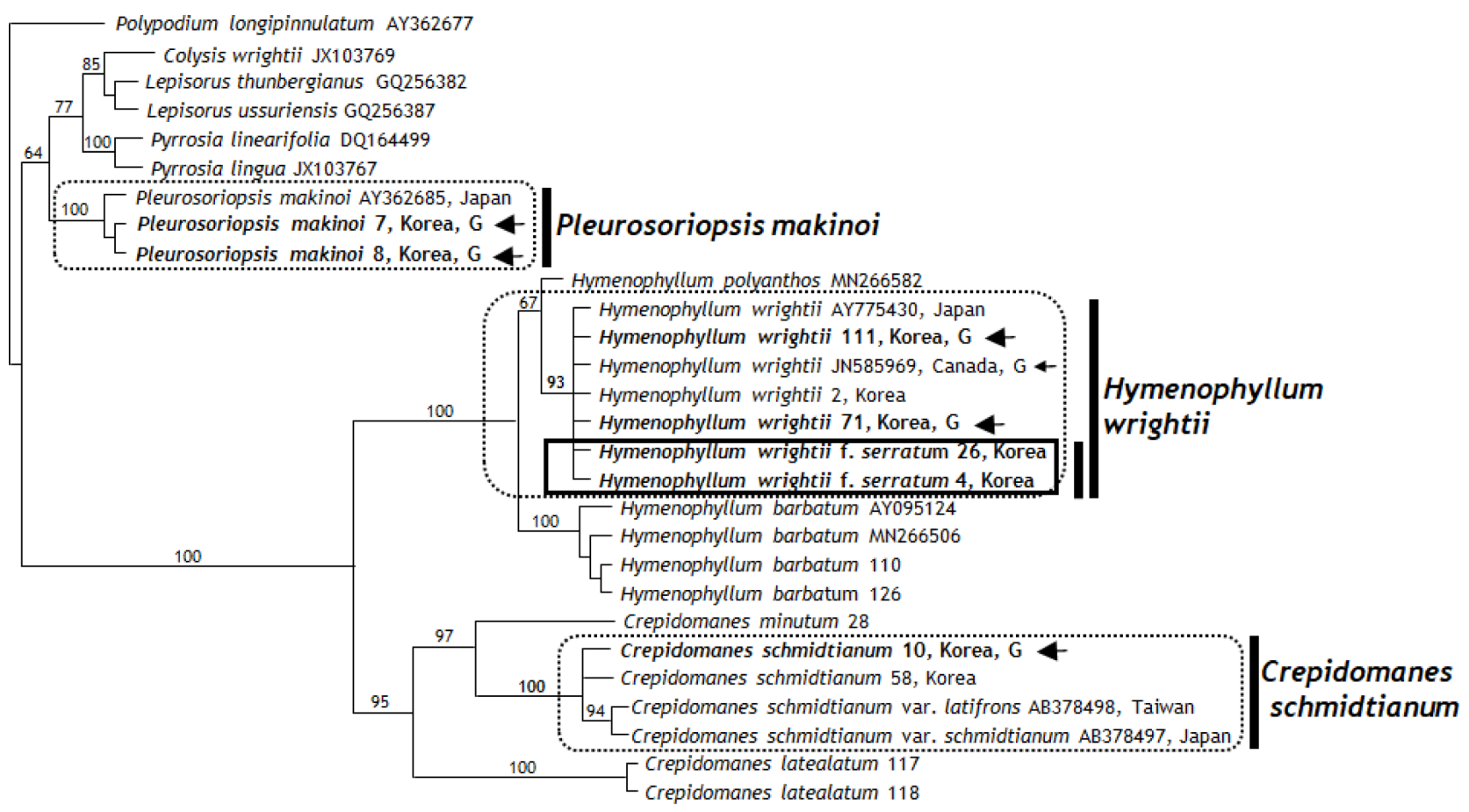

Fig. 4. Phylogenetic tree of three independent gametophytes, Hymenophyllum wrightii f. serratum, and related taxa deduced from rps4 gene and rps4-trnS intergenic spacer data. Bootstrap values $(>50 \%)$ by maximum parsimony method are shown above branches. Arrow and G, independent gametophytes.

coreanum (GenBank AB574717) and H. wrightii f. serratum formed the same clade with $82 \%$ bootstrap value (Fig. 3). Further study on Japanese and Korean populations of $H$. coreanum will be needed to confirm it. The same $100 \%$ same nucleotide positions among them were detected without $H$. wrightii f. serratum. In an analysis of the rps4 genes and rps4trnS IGS region (aligned $804 \mathrm{bp}$ ), the gametophytes and sporophytes of $H$. wrightii from Korea and the sporophyte from Japan (GenBank AY775430) (Hennequin et al, 2006) and the gametophytes of United States (GenBank JN585969) (Duffy et al., 2015) with $H$. wrightii f. serratum formed a clade with the strong support of a $93 \%$ bootstrap value. Among them, four different nucleotide positions $(0.49 \%)$ were detected. Based on the strong bootstrap value and $99 \%$ sequences, we confirm that the independent gametophytes of $H$. wrightii exist in Korea. These results are supported by morphological features, such as ribbon like gametophytes, linear gemmae, and many rhizoids.

Hymenophyllum wrightii f. serratum C. S. Lee \& K. Lee from Korea is distinguished from $H$. wrightii f. wrightii by its smaller height and broader basal leaf blades, broad-ovate lamina, larger sori, and serrated margins of involucres lips as a new taxon at the infraspecific level (Lee et al., 2014b). Hymenophyllum wrightii f. serratum were monophyletic within a Hymenophyllum wrightii clade based on the $r b c L$ region, and formed same clade within $H$. wrightii clade based on an analysis of the rps4 genes and rps4-trnS IGS region. Three unique genes were detected at the 320 position $(\mathrm{G}), 357$ position ( $\mathrm{T}$ ), and 465 position ( $\mathrm{T}$ ) in the $r b c L$ region. These molecular results were supported by the morphological characteristics as an intraspecific level of Hymenophyllum. Hymenophyllum wrightii f. serratum is a new taxon (Lee et al., 2014b) that should be treated as forma based on a similar cpDNA sequence to Hymenophyllum wrightii.

$r b c L$ region analysis indicated that the gametophytes of Pleurosoriopsis makinoi from Korea and sporophytes of $P$. makinoi from Japan (GenBank AY362613: Schneider et al., 2004; AB575285: Ebihara et al., 2010) form a clade with the strong support of a $100 \%$ bootstrap value (Fig. 3). On the other hand, Pleurosoriopsis makinoi exhibits two haplotypes refracting the geographic patterns: Japan and Korea types. Among the aligned 1,205 bp, only two nucleotide positions $(0.1 \%)$ were different sequences. In an analysis of the rps 4 genes and rps4-trnS IGS region (aligned $804 \mathrm{bp}$ ), the gametophytes of Pleurosoriopsis makinoi from Korea and sporophyte of P. makinoi from Japan (GenBank AY362685) (Schneider et al., 2004) form a clade with the strong support of a $100 \%$ bootstrap value. This cpDNA marker was more 
quickly evolved than $r b c L$ region as the previous paper pointed out (Ebihara et al., 2008). Among them, five different nucleotide positions $(0.6 \%)$ were detected. Based on $100 \%$ bootstrap value and $99 \%$ sequences, the independent gametophytes of P. makinoi are present in Korea. These results are supported by the morphological features, such as ribbon like gametophyte, gemmae shape, and a slight rhizoid presence. To prove the geographical variation between Japan, China, and Korea, more detailed research on the taxonomical revision of P. makinoi in the three countries will be needed.

An independent gametophyte was observed in the deep dint place of a moist rock, such as a small cave of a humid mountain around a valley in Gyeonggi-do, Gangwon-do, and Jeju-do province, Korea. Sporophytes of $P$. makinoi were rarely founded under the light condition of humid mountains throughout the country. Ebihara et al. (2019) examined the growth environment of the independent gametophytes of $P$. makinoi. They suggested that low light conditions in winter due to the planting of evergreen conifers caused the independence of gametophytes without growing sporophytes by detaching gemmae in winter. The gametophytes and independence gametophytes of $P$. makinoi were found together in same places. Therefore, further monitoring of sporophyte and gametophytes on a nationwide scale is recommended. Additional research with more detailed microenvironment conditions and habitats in Korea will be needed to clarify the independent gametophytes growth factors.

ORCID: Chang Shook LEE https://orcid.org/0000-0003-14446540; Kanghyup LEE https://orcid.org/0000-0002-7189-3235; Youngsim HWANG https://orcid.org/0000-0002-1773-9800

\section{Acknowledgments}

We thank Mr. Myeong Soo Kim at Fern Love society for first discovering and informing us, and also, the two anonymous reviews for the comments and suggestions.

\section{Conflict of Interest}

The authors declare that there are no conflicts of interest.

\section{Literature Cited}

Dassler, C. L. and D. R. Farrar. 2001. Significance of gametophyte form in long-distance colonization by tropical, epiphytic ferns. Brittonia 53: 352-369.

Duffy, A. M., M. C. Stensvold and D. R. Farrar. 2015. Indepen- dent gametophytes of Hymenophyllum wrightii in North America: not as rare as we thought. American Fern Journal 105: 45-55.

Ebihara, A. 2016. The Standard of Ferns and Lycophytes in Japan. Gakken Plus, Tokyo. Pp. 85-95.

Ebihara, A., J.-Y. Dubuisson, K. Iwatsuki, S. Hennequin and M. Ito. 2006. A taxonomic revision of Hymenophyllaceae. Blumea 51: 221-280.

Ebihara, A., D. R. Farrar and M. Ito. 2008. The sporophyte-less filmy fern of Eastern North America Trichomanes intricatum (Hymenophyllaceae) has the chloroplast genome of an Asian species. American Journal of Botany 95: 1645-1651.

Ebihara, A., K. Iwatsuki, M. Ito, S. Hennequin and J.-Y. Dubuisson. 2007. A global molecular phylogeny of the fern genus Trichomanes (Hymenophyllaceae) with special reference to stem anatomy. Botanical Journal of the Linnean Society 155 : $1-27$.

Ebihara, A., H. Iwatsuki, S. Matsumoto, S.-J. Lin, K. Iwatsuki, M. Takamiya, Y. Watano and M. Ito. 2005. Nuclear DNA, chloroplast DNA, and ploidy analysis clarified biological complexity of the Vandenboschia radicans complex (Hymenophyllaceae) in Japan and adjacent areas. American Journal of Botany 92: 1535-1547.

Ebihara, A., J. H. Nitta and M. Ito. 2010. Molecular species identification with rich floristic sampling: DNA barcoding the pteridophyte flora of Japan. PLoS ONE 5: e15136.

Ebihara, A., J. H. Nitta, Y. Matsumoto, Y. Fukazawa, M. Kurihara, H. Yokote, K. Sakuma, O. Azakami, Y. Hirayama and R. Imachi. 2019. Growth dynamics of independent gametophytes of Pleurosoriopsis makinoi (Polypodiaceae). Bulletin of the National Museum of Nature and Science, Series B (Botany) 45: 77-86.

Farrar, D. R. 1967. Gametophytes of four tropical fern genera reproducing independently of their sporophytes in the Southern Appalachians. Science 155: 1266-1267.

Farrar, D. R. 1985. Independent fern gametophytes in the wild. Proceedings of the Royal Society of Edinburgh 86B: 361-369.

Farrar, D. R. 1990. Species and evolution in asexually reproducing independent fern gametophytes. Systematic Botany 15 : 98-111.

Farrar, D. R. 1992. Trichomanes intricatum: the independent Trichomanes gametophyte in the eastern United States. American Fern Journal 82: 68-74.

Farrar, D. R., C. Dassler, J. E. Watkins and C. Skelton. 2008. Gametophyte ecology. In Biology and Evolution of Ferns and Lycophytes. Ranker, T. A. and C. H. Haufler (eds.), Cambridge University Press, Cambridge. Pp. 224-258.

Felsenstein, J. 1985. Confidence limits on phylogenies: an 
approach using the bootstrap. Evolution 39: 783-791.

Gibson, T., D. Higgins and J. Thompson. 1994. Clustal X Program. EMBL, Heidelberg.

Harrison, S. P., G. Yu, H. Takahara and I. C. Prentice. 2001. Palaeovegetation: Diversity of temperate plants in East Asia. Nature 413: $129-130$.

Hasebe, M., T. Omori, M. Nakazawa, T. Sano, M. Kato and K. Iwatsuki. 1994. $r b c L$ gene sequences provide evidence for the evolutionary lineages of leptosporangiate ferns. Proceedings of the National Academy of Sciences of the United States of America 91: 5730-5734.

Hennequin, S., A. Ebihara, M. Ito, K. Iwatsuki and J.-Y. Dubuisson. 2003. Molecular systematics of the fern genus Hymenophyllum s.l. (Hymenophyllaceae) based on chloroplastic coding and noncoding regions. Molecular Phylogenetics and Evolution 27: 283-301.

Hennequin, S., A. Ebihara, M. Ito, K. Iwatsuki and J.-Y. Dubuisson. 2006. New insights into the phylogeny of the genus Hymenophyllum s.l. (Hymenophyllaceae): revealing the polyphyly of Mecodium. Systematic Botany 31: 271-284.

Iwatsuki, K. 1985. The Hymenophyllaceae of Asia, excluding Malesia. Journal of the Faculty of Science, University of Tokyo, Section III 13: 501-551.

Kim, C., H.-G. Zha, T. Deng, H. Sun and S.-G. Wu. 2013. Phylogenetic relationship of Kontumia (Polypodiaceae) inferred from four chloroplast DNA regions. Journal of Systematic Evolution 51: 154-163.

Kreier, H.-P. and A. H. Schneider. 2006. Phylogeny and biogeography of the staghorn fern genus Platycerium (Polypodiaceae, Polypodiidae). American Journal of Botany 93: 217-225.

Krukowski, M. and K. Swierkosz. 2004. Discovery of the gametophytes of Trichomanes speciosum (Hymenophyllaceae: Pteridophyta) in Poland and its biogeographical importance. Fern Gazette 17: 79-85.

Kuo, L.-Y., C.-W. Chen, W. Shimohara, A. Ebihara, H. Kuddoh, H. Sato, Y.-M. Huang and W.-L. Chiou. 2017. Not only in the temperate zone: independent gametophytes of two vittarioid ferns (Pteridaceae, Polypodiales) in East Asian subtropics. Journal of Plant Research 130: 255-262.

Lee, C. S. and K. Lee. 2015. Pteridophytes of Korea: Lycophytes \& Ferns. Geobook, Seoul, 471 pp. (in Korean)

Lee, C. S. and K. Lee. 2018. Pteridophytes of Korea: Lycophytes $\&$ Ferns. 2nd ed. Geobook, Seoul, 489 pp. (in Korean)

Lee, C. S., K. Lee and Y. Hwang. 2014a. First record of Crepidomanes schmidtianum (Zanker ex Tasch.) K. Iwats. (Hymenophyllaceae) from Korea. Korean Journal of Plant Taxonomy 44: 1-5.

Lee, C. S., K. Lee, S. G. Lee and A. Ebihara. 2014b. A new taxon of Hymenophyllum (Hymenophyllaceae) H. wrightii f. serratum. Korean Journal of Plant Taxonomy. 44: 233-237.

Li, F.-W., B. C. Tan, V. Buchbender, R. C. Moran, G. Rouhan, C.N. Wang and D. Quanddt. 2009. Identifying a mysterious aquatic fern gametophyte. Plant Systematics and Evolution 281: 77-86.

Makgomol, K. and E. Sheffield. 2001. Gametophyte morphology and ultrastructure of the extremely deep shade fern, Trichomanes speciosum. New Phytologist 151: 243-255.

Morton, C. V. 1968. The genera, subgenera, and sections of the Hymenophyllaceae. Contributions from the United States National Herbarium 38: 153-214.

Nitta, J. H., A. Ebihara and M. Ito. 2011. Reticulate evolution in the Crepidomanes minutum species complex (Hymenophyllaceae). American Journal of Botany 98: 1782-1800.

Park, S. H., J. S. Kim and H. T. Kim. 2020. Study of the independent gametophytes found on Jeju Island in South Korea and the first record of the obligate independent gametophyte of Anthrophyum obovatum Baker. Ecology and Evolution 10: 7826-7838.

Pinson, J. B., S. M. Chambers, J. H. Nitta, L.-Y. Kuo and E. B. Sessa. 2016. The separation of generations: biology and biogeography of long-lived sporophyteless fern gametophytes. International Journal of Plant Sciences 178: 1-18.

Rumsey, F. J., A. C. Jermy and E. Sheffield. 1998. The independent gametophytic stage of Trichomanes speciosum Willd. (Hymenophyllaceae), the Killarney fern and its distribution in the British Isles. Watsonia 22: 1-19.

Sato, T. and A. Sakai. 1981. Cold tolerance of gametophytes and sporophytes of some cool temperate ferns native to Hokkaido. Canadian Journal of Botany 59: 604-608.

Schneider, H. and E. Schuetipelz. 2006. Identifying fern gametophytes using DNA sequences. Molecular Ecology Notes 6: 989-991.

Schneider, H., A. R. Smith, R. Cranfill, T. J. Hildebrand, C. H. Haufler and T. A. Ranker. 2004. Unraveling the phylogeny of polygrammoid ferns (Polypodiaceae and Grammitidaceae): exploring aspects of the diversification of epiphytic plants. Molecular Phylogenetics and Evolution 31: 1041-1063.

Smith, A. R. and R. B. Cranfill. 2002. Intrafamilial relationships of the thelypteroid ferns (Thelypteridaceae). American Fern Journal 92: 131-149.

Souza-Chies, T. T., G. Bittar, S. Nadot, L. Carter, E. Besin and B. Lejeune. 1997. Phylogenetic analysis of Iridaceae with parsimony and distance methods using the plastid gene rps4. Plant Systematics and Evolution 204: 109-123.

Swofford, D. L. 2002. PAUP*. Phylogenetic analysis using parsimony (*and other methods). Version 4.01b10. Sinauer Asso- 
ciates, Sunderland, MA.

Thompson, J. D., T. J. Gibson, F. Plewniak, F. Jeanmougin and D. G. Higgins. 1997. The Clustal X Windows Interface: flexible strategies for multiple sequence alignment aided by quality analysis tools. Nucleic Acids Research 25: 4876-4882.

Vasques, D. T., A. Ebihara, R. Y. Hirai, J. Prado and M. Ito. 2019. Phylogeny of Hymenophyllum subg. Mecodium (Hymenophyllaceae), with special focus on the diversity of the Hymenophyllum polyanthos species complex. Plant Systemat- ics and Evolution 305: 811-825.

Wang, L., X.-P. Qi, Q.-P. Xiang, J. Heinrichs, H. Schneider and X.C. Zhang. 2010. Phylogeny of the paleotropical fern genus Lepisorus (Polypodiaceae, Polypodiopsida) inferred from four chloroplast DNA regions. Molecular Phylogenetics and Evolution 54: 211-225.

Watkins, J. E., M. K. Mack and S. S. Mulkey. 2007. Gametophyte ecology and demography of epiphytic and terrestrial tropical ferns. American Journal of Botany 94: 701-708.

Appendix 1. Collection data of three independent gametophytes and Hymenophyllum wrightii f. serratum, and related taxa studied in molecular analyses (*DNA accession No. used from GenBank). Voucher specimens were deposited at Ewha Womans University Herbarium (EWH). Numbers in bold after each accession number are the same as in Figs. 3, 4. GenBank accession numbers listed in the following order: $r b c L$, * rps4-trnS, and rps4-trnS intergenic spacer.

Hymenophyllum wrightii Bosch: [2], KOREA. Jeju-do: Hallasan Mt., 30 Mar 2014, C. S. Lee \& K. Lee 1403010 (EWH), MT989370, *MW020609; [71], Gametophyte. Jeju-do: Hallasan Mt., 9 Nov 2014, C. S. Lee \& K. Lee 1411005 (EWH), MT989371, *MW020610; [111], Gametophyte. Jeju-do: Hallasan Mt., 14 Sep 2017, C. S. Lee \& K. Lee 1709004 (EWH), MT989372, *MW020611.

H. wrightii Bosch f. serratum C. S. Lee \& K. Lee: [4], KOREA, Jeju-do: Hallasan Mt., 31 Mar 2014, C. S. Lee \& K. Lee 1403015 (EWH), MT989373, *MT989375; [26], Jeju-do: Hallasan Mt., 2 Jun 2014, C. S. Lee \& K. Lee 1406015 (EWH), MT989374, *MT989376.

H. barbatum (Bosch) Baker: [110, 126], KOREA. Jeju-do: Hallasan Mt., 14 Sep 2017, C. S. Lee \& K. Lee 1709017-18 (EWH), MT98377, MT989378, *MT989379, *MT989380.

H. polyanthos (Sw.) Sw.: [3], KOREA. Jeju-do: Hallasan Mt., 31 Mar 2014, C. S. Lee \& K. Lee 1403020 (EWH), MT989381.

Crepidomanes schmidtianum (Zenker ex Tascher) K. Iwats.: [10], Gametophyte. KOREA. Gyeonggi-do: Hayansan Mt., 22 Feb 2014, C. S. Lee 1402002 (EWH), MT989382, * MT989384; [58], Geongsang-do: Jirisan Mt., 21 Oct 2014, C. S. Lee \& K. Lee 1410018 (EWH), MT9893833, *MT989385.

C. minutum (Blume) K. Iwats.: [28], KOREA. Jeju-do: Hallasan Mt., 1 Jun 2014, C. S. \& K. Lee 140617 (EWH), *MT989388.

C. latealatum (Bosch) Copel.: [117, 118], KOREA. Jeju-do: Hallasan Mt., 10 Oct 2017, C. S. \& K. Lee 1710012-3 (EWH), MT989393, MT989394, *MT989386, *MT989387.

Pleurosopsis makinoi (Maxim. ex Makino) Formin: [7, 8], Gametophyte. KOREA. Gyeonggi-do: Hwayansan Mt., 22 Feb 2014, C. S. Lee 1402008-9 (EWH), MT989389, MT989390, *MT989391, *MT989392. 